\title{
Effect of dexamethasone on the cisatracurium
} Korean Journal of Anesthesiology onset time and recovery profiles of

\author{
Keum Young So ${ }^{1,2}$, Sang Hun Kim ${ }^{1,2}, \mathrm{Ki}_{\text {Tae Jung }}^{1,2}$, and Dong Woo Kim ${ }^{1}$ \\ Department of Anesthesiology and Pain Medicine, ${ }^{1}$ Chosun University Hospital, ${ }^{2}$ Chosun University, School of \\ Medicine, Gwangju, Korea
}

Background: The effect of dexamethasone injection on cisatracurium-induced neuromuscular block was compared according to different injection time points.

Methods: One hundred seventeen patients were randomly assigned to three groups: $8 \mathrm{mg}$ of dexamethasone injected intravenously 2-3 h before anesthesia (group A), just before anesthesia induction (group B), and at the end of surgery (control group). Three minutes after anesthesia induction, intubation was performed without neuromuscular blockers, and acceleromyography was initiated. All patients received $0.05 \mathrm{mg} / \mathrm{kg}$ cisatracurium; the onset time and recovery profiles were recorded.

Results: Eighty patients were finally enrolled. The onset time (median [interquartile range], seconds) was significantly hastened in group A (520.0 [500.0-560.0], $\mathrm{n}=30)$ compared to that in group $\mathrm{B}(562.5$ [514.0-589.0], $\mathrm{n}=22)(\mathrm{P}=0.008)$ and control group (586.5 [575.0-642.5], $\mathrm{n}=28)(\mathrm{P}<0.001)$. The onset time in group $\mathrm{B}$ was faster than the control group $(\mathrm{P}$ $=0.015)$. The recovery time [mean $(95 \% \mathrm{CI})$ minutes] was significantly hastened in group A [28.5 (27.3-29.6)] compared to that in group $\mathrm{B}[32.3(31.0-33.6)](\mathrm{P}<0.001)$ and control group $[30.9(29.9-31.8)](\mathrm{P}=0.015)$. The total recovery time was significantly hastened more in group A [47.1 (45.5-48.6)] than group B [52.8 (51.6-54.0) minutes] $(\mathrm{P}<0.001)$ and control group [50.5 (48.7-52.3) minutes] $(\mathrm{P}=0.008)$.

Conclusions: A single dose of $8 \mathrm{mg}$ of dexamethasone hastened the onset and total recovery times of cisatracuriuminduced block by approximately 15 and $9 \%$, respectively if administered $2-3 \mathrm{~h}$ prior to surgery.

Key Words: Cisatracurium, Dexamethasone, Neuromuscular monitoring.

Corresponding author: Sang Hun Kim, M.D., Ph.D.

Department of Anesthesiology and Pain Medicine, Chosun University, School of Medicine, 309, Pilmun-daero, Dong-gu, Gwangju 61453, Korea

Tel: 82-62-220-3223, Fax: 82-62-223-2333

Email: ksh3223@chosun.ac.kr

ORCID: http://orcid.org/0000-0003-3869-9470

Received: June 24, 2016.

Revised: October 6, 2016 (1st); November 8, 2016 (2nd);

November 29, 2016 (3rd).

Accepted: November 29, 2016.

Korean J Anesthesiol 2017 April 70(2): 163-170

https://doi.org/10.4097/kjae.2017.70.2.163

\section{Introduction}

Dexamethasone is an effective agent for the prevention and treatment of postoperative nausea and vomiting (PONV), and its preoperative administration can provide better postoperative emotional state and physical comfort, and reduce the severity of postoperative pain and requirement of analgesics [1,2]. In addition, it is known that intravenous and perineural dexamethasone injection, as an adjuvant agent of regional anesthetics, can prolong the duration of analgesia and anesthesia by a variety of mechanisms, including peripheral and central mechanisms $[3,4]$.

Several investigators have been interested in determining whether chronic steroid medications can influence the time

(c) This is an open-access article distributed under the terms of the Creative Commons Attribution Non-Commercial License (http://creativecommons.org/ licenses/by-nc/4.0/), which permits unrestricted non-commercial use, distribution, and reproduction in any medium, provided the original work is properly cited. 
course of neuromuscular blockers (NMBs) during anesthesia, because some patients may take steroid medication for chronic diseases. They showed that chronic treatment with steroids shortened the duration of neuromuscular block in patients receiving atracurium or rocuronium $[5,6]$. However, during the perioperative period, a single-dose steroid, such as dexamethasone and prednisone, can be administered in patients for the prevention and treatment of PONV. It is not yet clear whether a single steroid injection would have an effect similar to chronic medication. A recent study reported that a single dose of $8 \mathrm{mg}$ dexamethasone showed different results in the time course of rocuronium, an aminosteroid non-depolarizing NMB, according to different injection time points. Dexamethasone $(8 \mathrm{mg})$ injection administered $2-3 \mathrm{~h}$ before surgery hastened the clinical duration, recovery index, and total recovery time of rocuronium; however, dexamethasone injection immediately before the induction of anesthesia did not influence the time course of the NMB [7]. However, to date, no studies have been conducted on the effect of dexamethasone on the onset time and recovery profiles (clinical duration, recovery index, recovery time, and total recovery time) of cisatracurium, a benzylisoquinolium nondepolarizing NMB.

In the present study, we tested our hypothesis that a single dose of dexamethasone administered $2-3 \mathrm{~h}$ prior to the induction of anesthesia would also hasten the onset time and recovery profiles of cisatracurium in patients receiving general anesthesia.

The primary end point was the onset time, which is the time from the start of cisatracurium injection to maximum depression of first twitch of the train-of-four (TOF). The secondary end points are clinical duration, recovery index, recovery time, and total recovery time.

\section{Materials and Methods}

This study was registered in the Clinical Research Information Service (CRIS, cris.nih.go.kr) on May 8, 2015, and the registration number is 'KCT0001519'.

This prospective, randomized, double-blind study was approved by our Institutional Review Board. After obtaining written informed consent from all patients or guardians, we enrolled 117 patients aged 20-65 years, belonging to the American Society of Anesthesiologists (ASA) physical status I or II, and scheduled to undergo elective surgery under general anesthesia. We excluded patients who had taken a steroid medication within the last $24 \mathrm{~h}$ or had received chronic steroid medication or medicines, such as furosemide, magnesium, or cephalosporin, known to influence the neuromuscular function. In addition, patients with neuromuscular disease, diabetes, a history of allergy to cisatracurium and dexamethasone, a body mass index (BMI) $>25$, as well as pregnant or breastfeeding women were excluded.
The study protocol adhered to the published guidelines for pharmacodynamic studies of NMBs [8].

All patients were premedicated intramuscularly with 0.05 $\mathrm{mg} / \mathrm{kg}$ of midazolam $30 \mathrm{~min}$ before anesthesia. Standard monitoring included an electrocardiogram, non-invasive blood pressure, end-tidal partial pressure of carbon dioxide $\left(\mathrm{ETCO}_{2}\right)$, and peripheral pulse oximetry. The patients and investigators were blinded to the study medications; a non-investigating nurse randomized medications by using a random number table, and produced them as indistinguishable, numbered syringes.

The patients were allocated to one of the three groups (Figs. 1 and 2). In group $\mathrm{A}$, the patients received $8 \mathrm{mg}$ dexamethasone in $0.9 \%$ normal saline (total volume, $2 \mathrm{ml}$ ) intravenously, 2-3 $\mathrm{h}$ before anesthesia in a ward, followed by $2 \mathrm{ml}$ of $0.9 \%$ normal saline just before the induction of anesthesia and at the end of surgery. In group B, the patients received $2 \mathrm{ml}$ of $0.9 \%$ normal saline intravenously, 2-3 h before anesthesia, followed by $8 \mathrm{mg}$ of dexamethasone in $0.9 \%$ normal saline (total volume $2 \mathrm{ml}$ ) intravenously just before the induction of anesthesia and $2 \mathrm{ml}$ of $0.9 \%$ normal saline intravenously at the end of surgery. In the control group, the patients received $2 \mathrm{ml}$ of $0.9 \%$ normal saline intravenously 2-3 h before anesthesia and just before induction of anesthesia. Subsequently, $8 \mathrm{mg}$ dexamethasone in $0.9 \%$ normal saline (total volume $2 \mathrm{ml}$ ) was administered intravenously at the end of surgery or after obtaining a TOF ratio of 0.9 , if the surgery was completed within $1 \mathrm{~h}$. General anesthesia was induced with propofol at a target effect-site concentration of $4 \mu \mathrm{g} /$ $\mathrm{ml}$ and remifentanil at $3 \mathrm{ng} / \mathrm{ml}$, followed by intubation without the aid of NMBs 3 min later. For the maintenance of anesthesia, the effect-site concentration of propofol and remifentanil was adjusted to maintain blood pressure within $20 \%$ change of initial rest systolic blood pressure and the bispectral index score in the range of 40 to 60 . The settings of mechanical ventilation with $50 \%$ oxygen-air mixture were also adjusted to maintain the $\mathrm{ETCO}_{2}$ between $35-45 \mathrm{mmHg}$.

Neuromuscular function was assessed by acceleromyography of the adductor pollicis muscle with TOF by using the neuromuscular transmission module, and it was displayed on a monitoring system (Anesthetic Monitoring System S $/ 5^{\mathrm{TM}}$, Datex-Ohmeda Inc., Helsinki, Finland). The arm was kept in the same position during the entire procedure. The stimulus current needed to achieve the maximal response of adductor pollicis muscle was automatically detected in each patient. After obtaining the supramaximal current, TOF stimuli were initiated to observe the potentiation of the first twitch (T1) of TOF and TOF ratios at $2 \mathrm{~Hz}$, every $15 \mathrm{~s}$, with square wave pulses of 0.2 ms duration. All patients were then administered $0.05 \mathrm{mg} / \mathrm{kg}$ of cisatracurium 3 min after intubation for the exclusion of hemodynamic effect on the time course of NMB [9]. We injected an additional dose of cisatracurium after obtaining the time taken 


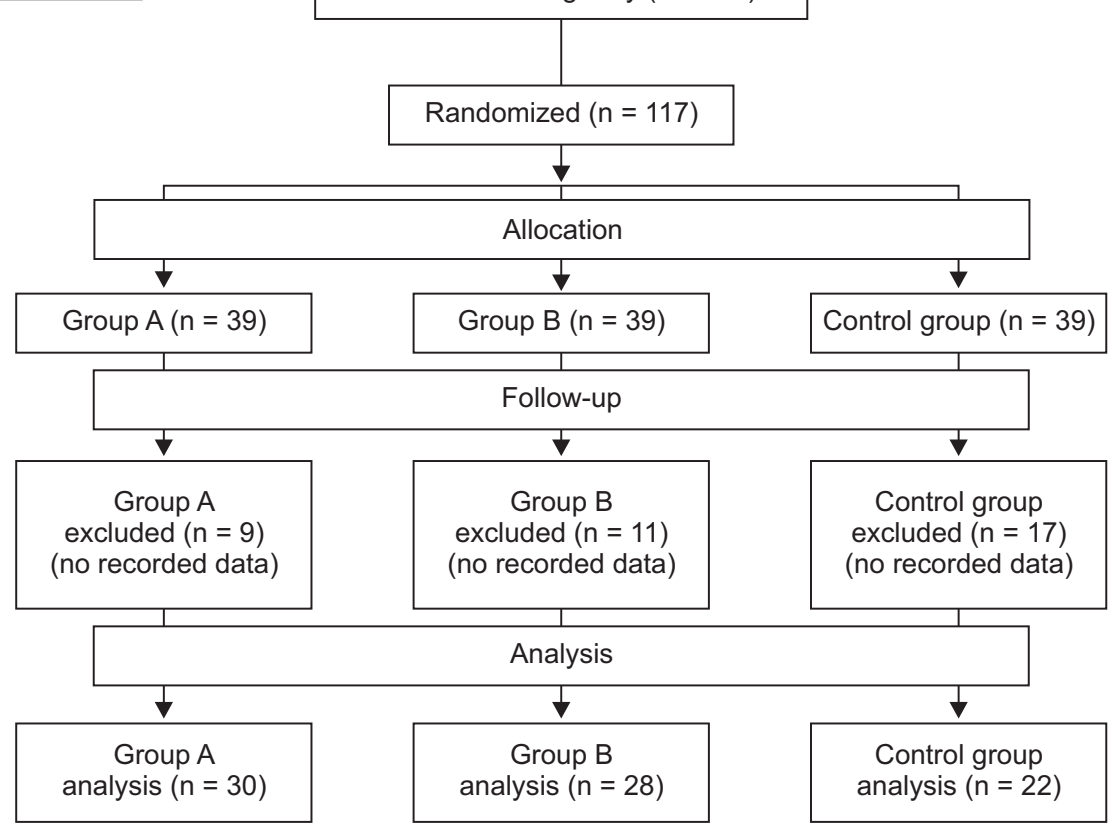

Fig. 1. CONSORT flow chart. Group A received $8 \mathrm{mg}$ dexamethasone in $0.9 \%$ normal saline (total volume $2 \mathrm{ml}$ ) intravenously $2-3 \mathrm{~h}$ before anesthesia. Group B received $8 \mathrm{mg}$ dexamethasone in $0.9 \%$ normal saline (total volume $2 \mathrm{ml}$ ) intravenously just before the induction of anesthesia. The control group received $8 \mathrm{mg}$ dexamethasone in $0.9 \%$ normal saline (total volume $2 \mathrm{ml}$ ) intravenously at the end of surgery or after obtaining a TOF ratio of 0.9 if the surgery was completed within $1 \mathrm{~h}$.

\begin{tabular}{llcl}
\hline & $\begin{array}{c}2-3 \mathrm{~h} \\
\text { before induction }\end{array}$ & $\begin{array}{c}\text { Just } \\
\text { before induction }\end{array}$ & The end of surgery \\
\hline $\begin{array}{l}\text { Group A } \\
\text { Goup B }\end{array}$ & $\begin{array}{c}\text { Dexamethasone } \\
\text { Normal saline } \\
\text { Normal saline }\end{array}$ & $\begin{array}{c}\text { Normal saline } \\
\text { Dexamethasone } \\
\text { Normal saline }\end{array}$ & $\begin{array}{c}\text { Normal saline } \\
\text { Normal saline } \\
\text { Dexamethasone }\end{array}$ \\
\hline
\end{tabular}

Fig. 2. Schematic protocol of this study. Group A received $8 \mathrm{mg}$ dexamethasone in $0.9 \%$ normal saline (total volume $2 \mathrm{ml}$ ) intravenously $2-3 \mathrm{~h}$ before anesthesia. Group B received $8 \mathrm{mg}$ dexamethasone in $0.9 \%$ normal saline (total volume $2 \mathrm{ml}$ ) intravenously just before the induction of anesthesia. The control group received $8 \mathrm{mg}$ dexamethasone in $0.9 \%$ normal saline (total volume $2 \mathrm{ml}$ ) intravenously at the end of surgery or after obtaining a TOF ratio of 0.9 , if the surgery was completed within $1 \mathrm{~h}$. TOF: train-of-four.

to reach a TOF ratio of 0.9 . Then, reversal agents (pyridostigmine $0.15 \mathrm{mg} / \mathrm{kg}$ with glycopyrrolate $0.2 \mathrm{mg} / 5 \mathrm{mg}$ of pyridostigmine) were administered at the end of surgery in these patients. If the patients showed vigorous activity, and the surgeons required more muscle relaxation before obtaining a TOF ratio of 0.9 , we injected additional $0.05 \mathrm{mg} / \mathrm{kg}$ of cisatracurium. These patients were excluded from statistical analysis. If the surgery was completed within $1 \mathrm{~h}$ and TOF ratio of 0.9 was not obtained, reversal agents (pyridostigmine $0.15 \mathrm{mg} / \mathrm{kg}$ with glycopyrrolate $0.2 \mathrm{mg} / 5$ $\mathrm{mg}$ of pyridostigmine) were administered after getting TOF ratio of 0.9 , under the continuous infusion of remifentanil and propofol. All patients were transferred to the recovery room after confirming a TOF ratio of 0.9 .

We measured and recorded the onset and recovery profiles as follows: (1) the time in seconds between the start of cisatra- curium injection and maximum T1 depression (onset time), (2) the time in minutes between the start of cisatracurium injection and $25 \%$ twitch height recovery of T1 (clinical duration), (3) the time in minutes between 25 and $75 \%$ twitch height recovery of T1 (recovery index), (4) the time in minutes between the $25 \%$ twitch height recovery of $\mathrm{T} 1$ and recovery of neuromuscular block to a TOF ratio of 0.9 (recovery time), (5) the time between the start of cisatracurium injection till the recovery of neuromuscular block to a TOF ratio of 0.9 (total recovery time), and (6) the incidence of incomplete neuromuscular block (below 95\% T1 depression). The age, sex, ASA physical status, height, weight, and BMI were also noted.

The necessary sample size was calculated by taking the level of statistical significance as $\alpha=0.05$ and $\beta=0.2$ using an expected effect size of 0.3 , which is larger than the medium effect 
size (0.25) suggested by Cohen, owing to lack of evidence for calculating the effect size [10]. We required 37 patients in each group, and we enrolled 39 patients given the assumption of a $5 \%$ dropout rate.

\section{Statistical analysis}

We excluded data of patients from whom we could not get any results of the onset time, clinical duration, recovery index, recovery time, or total recovery time. SPSS (Windows ver. 21.0, IBM Corp., Armonk, NY, USA) was used for statistical analysis. All measured values are presented as means \pm SD, mean $(95 \%$ $\mathrm{CI}$ ), median (interquartile range [IQR]), or number of patients (\%). The BMI, onset time, clinical duration, and recovery index were compared using Kruskal-Wallis test because of the skewed distribution. If a significant intergroup difference was found, the post-hoc Mann-Whitney $U$ test was used. The age, height, and recovery and total recovery times were analyzed using one-way ANOVA for normally distributed data. If a significant intergroup difference was found, the Scheffés post-hoc test was used. The sex, ASA physical status, and incidence of incomplete neuromuscular block were analyzed by the $\chi^{2}$ test. $\mathrm{P}<0.017$ rather than $\mathrm{P}<0.05$ was considered to indicate statistical significance in $\mathrm{BMI}$, onset time, clinical duration, and recovery index. Otherwise, $\mathrm{P}<0.05$ was considered to indicate statistical significance.

\section{Results}

Eighty patients were ultimately enrolled in this study. Thirtyseven patients (9 patients in group A, 11 patients in group B, and 17 patients in control group) were excluded from the data analysis because their clinical duration and recovery index were not calculated owing to below 75\% T1 depression (Fig. 1). No significant differences in sex, ASA physical status, age, height, weight, and BMI were found among the groups (Table 1).

Table 1. Patient Characteristics

\begin{tabular}{lccc}
\hline & Group A $(\mathrm{n}=30)$ & Group B $(\mathrm{n}=28)$ & Control group $(\mathrm{n}=22)$ \\
\hline Sex $(\mathrm{M} / \mathrm{F})$ & $20 / 10$ & $22 / 6$ & $14 / 8$ \\
ASA physical status (I/II) & $22 / 8$ & $21 / 7$ & $17 / 5$ \\
Age (yr) & $41.0 \pm 12.9$ & $37.0 \pm 12.6$ & $37.7 \pm 13.5$ \\
Height (cm) & $169.3 \pm 8.6$ & $173.0 \pm 7.0$ & $169.9 \pm 7.9$ \\
Weight (kg) & $64.0 \pm 8.7$ & $68.3 \pm 8.7$ & $66.4 \pm 9.6$ \\
BMI & $22.3 \pm 1.7$ & $22.7 \pm 1.9$ & $22.9 \pm 2.0$ \\
\hline
\end{tabular}

The values are expressed as mean $\pm \mathrm{SD}$, or number of patients. There are no significant differences among groups. Group A received $8 \mathrm{mg}$ dexamethasone in $0.9 \%$ normal saline (total volume $2 \mathrm{ml}$ ) intravenously $2-3 \mathrm{~h}$ before anesthesia. Group B received $8 \mathrm{mg}$ dexamethasone in $0.9 \%$ normal saline (total volume $2 \mathrm{ml}$ ) intravenously just before the induction of anesthesia. The control group received $8 \mathrm{mg}$ dexamethasone in $0.9 \%$ normal saline (total volume $2 \mathrm{ml}$ ) intravenously at the end of surgery or after obtaining a train-of-four ratio of 0.9 , if the surgery was completed within $1 \mathrm{~h}$. ASA: American Society of Anesthesiologists, BMI: body mass index.

Table 2. The Effect of Dexamethasone on the Onset Time and Recovery Profiles of Cisatracurium-induced Neuromuscular Block

\begin{tabular}{lccc}
\hline & Group A $(\mathrm{n}=30)$ & Group B $(\mathrm{n}=28)$ & Control group (n=22) \\
\hline Onset time (s) & $520.0[500.0-560.0]^{*, \dagger}$ & $562.5[514.0-589.0]^{*}$ & $586.5[575.0-642.5]$ \\
Clinical duration (min) & $18.7[16.7-20.0]$ & $19.7[18.7-21.5]$ & $19.3[18.5-21.6]$ \\
Recovery index (min) & $16.3[13.9-18.4]$ & $18.7[15.3-19.4]$ & $17.9[16.5-20.3]$ \\
Recovery time (min) & $28.5(27.3-29.6)^{\neq, \S}$ & $32.3(31.0-33.6)$ & $30.9(29.9-31.8)$ \\
Total recovery time (min) & $47.1(45.5-48.6)^{\ddagger, \S}$ & $52.8(51.6-54.0)$ & $50.5(48.7-52.3)$ \\
ICNMB (n [\%]) & $19(63.3)$ & $19(67.9)$ & $20(90.9)$ \\
\hline
\end{tabular}

The values are expressed as mean (95\% CI), median [interquartile range], or number of patients (\%). Group A received 8 mg dexamethasone in $0.9 \%$ normal saline (total volume $2 \mathrm{ml}$ ) intravenously $2-3 \mathrm{~h}$ before anesthesia. Group B received $8 \mathrm{mg}$ dexamethasone in $0.9 \%$ normal saline (total volume 2 $\mathrm{ml}$ ) intravenously just before the induction of anesthesia. The control group received $8 \mathrm{mg}$ dexamethasone in $0.9 \%$ normal saline (total volume $2 \mathrm{ml}$ ) intravenously at the end of surgery or after obtaining a train-of-four (TOF) ratio of 0.9 , if the surgery was completed within $1 \mathrm{~h}$. Onset time: the time in seconds between the start of cisatracurium injection and maximum the first twitch (T1) depression, clinical duration: the time in minutes between the start of cisatracurium injection and $25 \%$ twitch height recovery of T1, recovery index: the time in minutes between 25 and $75 \%$ twitch height recovery of T1, recovery time: the time in minutes between the $25 \%$ twitch height recovery of $\mathrm{T} 1$ and recovery of neuromuscular block to a TOF ratio of 0.9 , total recovery time: the time between the start of cisatracurium injection to the recovery of neuromuscular block to a TOF ratio of 0.9 . ICNMB: incomplete neuromuscular block (below 95\% T1 depression). ${ }^{*, \dagger} \mathrm{P}<0.017$ rather than $\mathrm{P}<0.05$ was considered to indicate statistical significance in onset time, clinical duration, and recovery index after multiple comparisons compared with control group and group $\mathrm{B}$, respectively. ${ }^{\text {f } \S_{\mathrm{P}}<0.05 \text { was }}$ considered to indicate statistical significance in otherwise compared with control group and group B, respectively. 
The one-way ANOVA analysis and Kruskal-Wallis test showed significant differences among groups in the onset, recovery, and total recovery times. However, there were no significant differences in the clinical duration and recovery index among groups (Table 2 ).

The onset time (median [IQR] seconds) was significantly hastened in group A (520.0 [500.0-560.0] s, $\mathrm{n}=30)$ compared to that in group $\mathrm{B}(562.5[514.0-589.0] \mathrm{s}, \mathrm{n}=22)(\mathrm{P}=0.008)$ and $\mathrm{C}(586.5$ [575.0-642.5] s, $\mathrm{n}=28)(\mathrm{P}<0.001$, Table 2$)$. The onset time in group $\mathrm{B}$ was also faster than control group $(\mathrm{P}=0.015$, Table 2). The differences in onset time [mean (95\% CI) min] were -41.9 ( -91.9 to 8.1$),-95.4(-148.8$ to 42.0$)$, and -53.5 $(-107.7$ to 0.9$)$ seconds, between group $A$ and B, group A and control group, and group B and control group, respectively.

The recovery time [mean $(95 \% \mathrm{CI}) \mathrm{min}$ ] was significantly hastened in group A compared to that in group B [28.5 (27.3$29.6)$ vs. 32.3 (31.0-33.6) $\mathrm{min}, \mathrm{P}<0.001]$ and control group [28.5 (27.3-29.6) vs. 30.9 (29.9-31.8) $\mathrm{min}, \mathrm{P}=0.015$ ] (Table 2). However, we found no significant difference between group $B$ and the control group $(\mathrm{P}=0.241)$. The differences in recovery time [mean $(95 \% \mathrm{CI}) \mathrm{min}$ ] were $-3.8(-5.7$ to -1.9$),-2.4(-4.5$ to -0.4 ), and 1.4 ( -0.7 to 3.5 ) min, between group A and B, group $\mathrm{A}$ and control group, and group B and control group, respectively.

The total recovery time [mean $(95 \% \mathrm{CI}) \mathrm{min}$ ] was significantly hastened in group A [47.1 (45.5-48.6) min] compared to that in group $\mathrm{B}$ [52.8 $(51.6-54.0) \mathrm{min}](\mathrm{P}<0.001)$ and control group [50.5 (48.7-52.3) $\mathrm{min}, \mathrm{P}=0.008$ ] (Table 2). However, we found no significant difference between group $\mathrm{B}$ and the control group $(\mathrm{P}=0.108)$. The differences in total recovery time [mean $(95 \% \mathrm{CI}) \mathrm{min}]$ were $-5.7(-8.2$ to -3.3$),-3.4(-6.1$ to -0.8$)$, and $2.3(-0.4$ to 5.0) minutes, between group A and B, group A and control group, and group B and control group, respectively.

The incidence of incomplete neuromuscular block was not significantly different among the groups, with 63.3, 67.9, and $90.9 \%$ incidence in $A(n=30), B(n=28)$, and control $(n=22)$ groups, respectively ( $\mathrm{P}=0.07$, Table 2 ). However, if the missing data was included, it was significant different among the groups with 71.8, 74.4, and 94.9\% incidence in groups A $(n=39), B(n$ $=39)$, and control $(\mathrm{n}=39)$, respectively $(\mathrm{P}=0.019)$.

\section{Discussion}

In the present study, $8 \mathrm{mg}$ of dexamethasone hastened the onset time of cisatracurium when injected intravenously $2-3 \mathrm{~h}$ before surgery and immediately before the induction of anesthesia. It also hastened the recovery and total recovery times of cisatracurium when injected intravenously $2-3 \mathrm{~h}$ before surgery. However, its administration immediately before the induction of anesthesia did not show any significant effect on the recovery profiles of cisatracurium.

It is known that NMBs can interact with many drugs, such as most antibacterials, procainamide, quinidine, magnesium, calcium antagonists, phenytoin, lithium, steroids, and furosemide [11]. In particular, the studies on interaction between NMBs and steroids were usually focused in patients receiving chronic steroid medication $[5,6,12]$. These reports documented that chronic steroid medication could interact with NMBs, resulting in resistance to NMB action. The onset time showed the controversial effect according to NMBs, while the recovery profiles such as clinical duration and total recovery time were hastened. However, it is not clear whether a single steroid injection would have a similar effect. We frequently encounter patients requiring a perioperative single-dose injection of dexamethasone because of its antiemetic, anti-inflammatory, and analgesic properties, rather than patients receiving chronic steroid medication [1,2,13-15]. For the prevention of PONV, dexamethasone is commonly injected prior to surgery at the induction of anesthesia, owing to its delayed onset [16,17]. Recently, Soltesz et al. [7] examined whether dexamethasone required more time to influence the time course of NMB by analyzing its interaction with rocuronium. They documented that a single-dose injection of 8 mg dexamethasone $2-3 \mathrm{~h}$ before surgery hastened the clinical duration, recovery index, and total recovery time, while injection administered $15 \mathrm{~min}$ prior to rocuronium administration did not attenuate the effect of rocuronium. The present study using cisatracurium also showed that the recovery profiles, except for clinical duration and recovery index, were hastened in patients who received $8 \mathrm{mg}$ dexamethasone $2-3 \mathrm{~h}$ before anesthesia; however, dexamethasone injection just before induction did not significantly influence the effect of cisatracurium. These findings can be supported by the results of Robinson's study [18], in which betamethasone induced resistance to nondepolarizing NMB by increasing the $\mathrm{ED}_{50}$ for atracurium by $27 \%$ and vecuronium by $45 \%$. Furthermore, the onset time was hastened by a single-dose injection of $8 \mathrm{mg}$ dexamethasone $2-3 \mathrm{~h}$ before surgery in the present study; however, in the study of Soltesz et al. [7] dexamethasone did not influence the onset time according to different injection time points. This discrepancy can be explained by the incidence of incomplete neuromuscular block. Soltesz et al. [7] reported that $0.3 \mathrm{mg} / \mathrm{kg}$ rocuronium $\left(\mathrm{ED}_{95}\right)$ led to complete neuromuscular block in nearly all patients; however, the present study showed high incidence of incomplete neuromuscular block.

Several mechanisms underlying the interaction between steroids and NMBs have been suggested. First, steroids have a direct facilitatory effect at the impulse-generating end of the motor nerve axon, and they act presynaptically to stimulate the synthesis and release of acetylcholine [19-22]. In addition, steroids amplify neuromuscular transmission by the predominant 
activation of presynaptic facilitatory adenosine $\mathrm{A}_{2 \mathrm{~A}}$ receptors leading to synaptic vesicle redistribution [23]. This activation of $\mathrm{A}_{2 \mathrm{~A}}$ receptors modulates the interaction of presynaptic nicotinic and muscarinic auto-receptor regulation on motor nerve endings to sustain acetylcholine release. Ultimately, the concentration of acetylcholine may be high enough at muscle-type nicotinic acetylcholine receptors, and non-depolarizing NMBs competitively inhibit the binding of acetylcholine to the receptors. In the animal study using mouse isolated phrenic nervediaphragm and rat external popliteal/sciatic nerve-tibialis anterior muscle preparations, it was observed that dexamethasone and prednisolone prevented neuromuscular block induced by $\mathrm{d}$ tubocurarine via aforementioned mechanism [21,22]. Therefore, an increased dose of d-tubocurarine is sufficient for neuromuscular block [22]. In addition, sufficient time interval between the steroid and NMB injection is required for presynaptic effect to stimulate the synthesis and release of acetylcholine by a single injection of dexamethasone. It was found that a 2-3 h time interval can attenuate the neuromuscular block of aminosteroid and benzylisoquinolium nondepolarizing NMBs in this study as well as that of Soltesz's [7]. However, the exact time interval required to develop drug interaction with NMBs could not be defined. Second, steroids are associated with inhibition of muscletype nicotinic acetylcholine receptor function [24] and increase in the expression of this receptor at extracellular sites [25]. Increased expression of nicotinic acetylcholine receptor resulted in dexamethasone-induced hyposensitivity to non-depolarizing NMBs, and this hyposensitivity was highest in the group using atracurium and least in the group using rocuronium [25]. However, a single injection of dexamethasone does not have a direct antagonistic effect on the nicotinic acetylcholine receptor, because the brief time interval from dexamethasone to NMB injection did not attenuate the neuromuscular block of rocuronium and cisatracurium in our study as well as that of Soltesz [7].

There are some limitations associated with the present study. First, we used $\mathrm{ED}_{95}$ of cisatracurium $(0.05 \mathrm{mg} / \mathrm{kg})$, which is lower than the clinical intubation dose, because the guideline recommends using low doses to assess the onset and recovery profiles of NMB $[8,26]$. This dose was not sufficient to induce complete neuromuscular block above 95\% T1 depression. The incidence of incomplete neuromuscular block was 63.3, 67.9, and $90.9 \%$ in groups A, B, and control, respectively, and if the missing data were included, it was increased to 71.8, 74.4, and $94.9 \%$ in groups A, B, and control, respectively, owing to below 75\% T1 depression. Second, we performed endotracheal intubation without NMB, which is not recommended for routine clinical situations. If we performed this procedure after injection of NMBs, the results of onset time and recovery profiles might be influenced by hemodynamic changes caused by laryngoscopy and endotracheal intubation. Third, we did not show intubation- induced hemodynamic changes because we did not record them despite the observation for maintaining blood pressure within $20 \%$ changes of initial rest systolic blood pressure. However, Guignard et al. [9] documented that the target effect-site concentration of remifentanil between 2 and $4 \mathrm{ng} / \mathrm{ml}$ significantly reduced the increase in mean arterial blood pressure and heart rate associated with endotracheal intubation, especially 2 or 5 min after intubation when compared with that of pre-induction and pre-laryngoscopy values. In addition, they showed that the maintenance of hemodynamic variables within $20 \%$ changes could be achieved in this range of target effect-site concentration of remifentanil. Therefore, in this study, we used remifentanil at a target effect-site concentration of $3 \mathrm{ng} / \mathrm{ml}$, and injected cisatracurium 3 min after endotracheal intubation, which was the time in which blood pressure could be maintained within $20 \%$ changes by adjusting the concentration of remifentanil. Fourth, we could not establish the precise effect size because of lack of previously published studies on effect size. Therefore, we calculated the necessary sample size with an expected effect size of 0.3 , which is larger than that of medium standardized effect size (0.25) suggested by Cohen. However, in this study, the differences in onset time between group A and B and group A and control group were 41.9 and 95.4 s, respectively. The differences in total recovery time between group $\mathrm{A}$ and $\mathrm{B}$ and group $\mathrm{A}$ and control group were 5.7 and $3.4 \mathrm{~min}$, respectively. The differences of onset time between the groups are sufficient to be considered as clinical meaningful significance, whereas the differences of recovery and total recovery times between the groups are not. Finally, the power of the present study may be decreased because of the $33.4 \%$ dropout rate due to below $75 \%$ T1 depression. Despite these limitations, this study showed that the onset time was significantly hastened with meaningful statistical difference by the administration of dexamethasone $2-3 \mathrm{~h}$ before surgery.

In conclusion, a single $8 \mathrm{mg}$ of dexamethasone accelerated the onset and total recovery times of cisatracurium-induced neuromuscular block by approximately 15 and $9 \%$, respectively, if administered 2-3 h before surgery. Therefore, clinicians should be aware that insufficient neuromuscular block is possible in patients who require a high-dose steroid preoperatively and in patients who undergo surgery that requires deep neuromuscular block. In addition, to obtain results that reflect the clinical conditions, an additional study with enough effective size and power in which clinical intubation doses of NMBs are used is necessary.

\section{Acknowledgments}

This study was supported by research fund from Chosun University, 2015. 


\section{ORCID}

Keum Young So, http://orcid.org/0000-0002-1511-7418

Sang Hun Kim, http://orcid.org/0000-0003-3869-9470

Ki Tae Jung, http://orcid.org/0000-0002-2486-9961

Dong Woo Kim, http://orcid.org/0000-0002-5604-848X

\section{References}

1. Gan TJ, Diemunsch P, Habib AS, Kovac A, Kranke P, Meyer TA, et al. Consensus guidelines for the management of postoperative nausea and vomiting. Anesth Analg 2014; 118: 85-113.

2. Murphy GS, Szokol JW, Greenberg SB, Avram MJ, Vender JS, Nisman M, et al. Preoperative dexamethasone enhances quality of recovery after laparoscopic cholecystectomy: effect on in-hospital and postdischarge recovery outcomes. Anesthesiology 2011; 114: 882-90.

3. Abdallah FW, Johnson J, Chan V, Murgatroyd H, Ghafari M, Ami N, et al. Intravenous dexamethasone and perineural dexamethasone similarly prolong the duration of analgesia after supraclavicular brachial plexus block: a randomized, triple-arm, double-blind, placebocontrolled trial. Reg Anesth Pain Med 2015; 40: 125-32.

4. Murni Sari Ahmad A, Azarinah I, Esa K, Khairulamir Z, Hamidah I, Norsidah Abdul M. Intravenous dexamethasone in combination with caudal block prolongs postoperative analgesia in pediatric daycare surgery. Middle East J Anaesthesiol 2015; 23: 177-83.

5. Soltész S, Mencke T, Stunz M, Diefenbach C, Ziegeler S, Molter GP. Attenuation of a rocuronium-induced neuromuscular block in patients receiving prednisolone. Acta Anaesthesiol Scand 2009; 53: 443-8.

6. Soltész S, Mencke T, Mey C, Röhrig S, Diefenbach C, Molter GP. Influence of a continuous prednisolone medication on the time course of neuromuscular block of atracurium in patients with chronic inflammatory bowel disease. Br J Anaesth 2008; 100: 798-802.

7. Soltész S, Fraisl P, Noé KG, Hinkelbein J, Mellinghoff H, Mencke T. Dexamethasone decreases the duration of rocuronium-induced neuromuscular block: a randomised controlled study. Eur J Anaesthesiol 2014; 31: 417-22.

8. Fuchs-Buder T, Claudius C, Skovgaard LT, Eriksson LI, Mirakhur RK, Viby-Mogensen J. Good clinical research practice in pharmacodynamic studies of neuromuscular blocking agents II: the Stockholm revision. Acta Anaesthesiol Scand 2007; 51: 789-808.

9. Guignard B, Menigaux C, Dupont X, Fletcher D, Chauvin M. The effect of remifentanil on the bispectral index change and hemodynamic responses after orotracheal intubation. Anesth Analg 2000; 90: 161-7.

10. Cohen J. A power primer. Psychol Bull 1992; 112: 155-9.

11. Feldman S, Karalliedde L. Drug interactions with neuromuscular blockers. Drug Saf 1996; 15: 261-73.

12. Parr SM, Robinson BJ, Rees D, Galletly DC. Interaction between betamethasone and vecuronium. Br J Anaesth 1991; 67: 447-51.

13. De Oliveira GS Jr, Almeida MD, Benzon HT, McCarthy RJ. Perioperative single dose systemic dexamethasone for postoperative pain: a meta-analysis of randomized controlled trials. Anesthesiology 2011; 115: 575-88.

14. De Oliveira GS Jr, Castro-Alves LJ, Ahmad S, Kendall MC, McCarthy RJ. Dexamethasone to prevent postoperative nausea and vomiting: an updated meta-analysis of randomized controlled trials. Anesth Analg 2013; 116: 58-74.

15. Waldron NH, Jones CA, Gan TJ, Allen TK, Habib AS. Impact of perioperative dexamethasone on postoperative analgesia and side-effects: systematic review and meta-analysis. Br J Anaesth 2013; 110: 191-200.

16. Wang JJ, Ho ST, Tzeng JI, Tang CS. The effect of timing of dexamethasone administration on its efficacy as a prophylactic antiemetic for postoperative nausea and vomiting. Anesth Analg 2000; 91: 136-9.

17. Holte K, Kehlet H. Perioperative single-dose glucocorticoid administration: pathophysiologic effects and clinical implications. J Am Coll Surg 2002; 195: 694-712.

18. Robinson BJ, Lee E, Rees D, Purdie GL, Galletly DC. Betamethasone-induced resistance to neuromuscular blockade: a comparison of atracurium and vecuronium in vitro. Anesth Analg 1992; 74: 762-5.

19. Veldsema-Currie RD, Wolters E, Leeuwin RS. The effect of corticosteroids and hemicholinium-3 on choline uptake and incorporation into acetylcholine in rat diaphragm. Eur J Pharmacol 1976; 35: 399-402.

20. Dalkara T, Onur R. Facilitatory effects of dexamethasone on neuromuscular transmission. Exp Neurol 1987; 95: 116-25.

21. Dal Belo CA, Leite GB, Fontana MD, Corrado AP, Zanandréa Baso AC, Moreno Serra CS, et al. New evidence for a presynaptic action of prednisolone at neuromuscular junctions. Muscle Nerve 2002; 26: 37-43.

22. Leeuwin RS, Veldsema-Currie RD, van Wilgenburg H, Ottenhof M. Effects of corticosteroids on neuromuscular blocking actions of d-tubocurarine. Eur J Pharmacol 1981; 69: 165-73.

23. Oliveira L, Costa AC, Noronha-Matos JB, Silva I, Cavalcante WL, Timóteo MA, et al. Amplification of neuromuscular transmission by methylprednisolone involves activation of presynaptic facilitatory adenosine A2A receptors and redistribution of synaptic vesicles. Neuropharmacology 2015; 89: 64-76.

24. Ke L, Lukas RJ. Effects of steroid exposure on ligand binding and functional activities of diverse nicotinic acetylcholine receptor subtypes. J 
Neurochem 1996; 67: 1100-12.

25. Chen D, Yang MR, Huang LN, Qiu YW, Li ST. Different magnitude of resistance to non-depolarizing muscle relaxants in dexamethasonetreated rat diaphragm associated with altered acetylcholine receptor expression. Genet Mol Res 2014; 13: 5892-900.

26. Bryson HM, Faulds D. Cisatracurium besilate. A review of its pharmacology and clinical potential in anaesthetic practice. Drugs 1997; 53: 848-66. 